\title{
Clinical Outcome of Arthroscopic Partial Repair of Large to Massive Posterosuperior Rotator Cuff Tears: Medialization of the Attachment Site of the Rotator Cuff Tendon
}

\author{
Kwang Won Lee, MD, Gyu Sang Lee, MD, Dae Suk Yang, MD, Seong Ho Park, MD, \\ Young Sub Chun, MD, Won Sik Choy, MD \\ Department of Orthopedic Surgery, Eulji University School of Medicine, Daejeon, Korea
}

Background: The goal of this study was to evaluate the clinical and radiological outcomes of arthroscopic partial repair with medialization of the attachment site of the rotator cuff tendon and to identify prognostic factors affecting rotator cuff healing in patients with irreparable large to massive posterosuperior rotator cuff tears.

Methods: Between July 2012 and March 2016, 42 patients with irreparable large to massive posterosuperior rotator cuff tears underwent an arthroscopic partial repair with medialization of the attachment site of the rotator cuff tendon. All patients had a minimum of 2-year follow-up (mean, $35.4 \pm 7.3$ months). Clinical evaluation was performed using the visual analog scale, the University of California, Los Angeles shoulder rating scale, Constant score, and active range of motion. Radiological evaluation was performed using magnetic resonance imaging and simple radiography.

Results: Clinical outcomes at the final follow-up improved significantly compared with the preoperative values (all $p<0.001)$. The failure rate was 23.8\% (10/42); however, clinical outcomes significantly improved regardless of cuff healing (all $p<0.001)$. The mean acromiohumeral distance was $6.5 \pm 1.7 \mathrm{~mm}$ (range, 3.2-9.7 mm) before surgery and $6.3 \pm 1.6 \mathrm{~mm}$ (range, 2.8-9.5 mm) at the final follow-up. Preoperative acromiohumeral distance was associated with failure of cuff healing in the univariate analysis $(p=0.043)$ and multivariate analysis $(p=0.048)$. A receiver operating characteristic curve was used to determine the predictive cutoff value for the smallest preoperative acromiohumeral distance for successful healing, which was calculated as $5.3 \mathrm{~mm}$.

Conclusions: Despite healing failure, arthroscopic partial repair with medialization can be a possible treatment option for irreparable large to massive posterosuperior rotator cuff tears because of the improvement in clinical outcome. The shorter preoperative acromiohumeral distance was the single most important factor negatively affecting cuff healing, and the likelihood of success of healing might be improved if a repair is performed when the preoperative acromiohumeral distance is $<5.3 \mathrm{~mm}$.

Keywords: Shoulder, Rotator cuff injuries, Prognosis

Rotator cuff tears are a common cause of shoulder joint

Received August 12, 2019; Accepted November 5, 2019

Correspondence to: Dae Suk Yang, MD

Department of Orthopedic Surgery, Eulji University School of Medicine, 95 Dunsanseo-ro, Seo-gu, Daejeon 35233, Korea

Tel: +82-42-611-3279, Fax: +82-42-611-3283

E-mail: yds123@eulji.ac.kr pain and functional disorder in adults. ${ }^{1,2)}$ Anatomical restoration of a torn rotator cuff through surgical repair is essential for pain relief and recovery of range of motion (ROM) and muscle strength. However, direct bone-totendon repair is not easy to perform in large to massive rotator cuff tears due to fatty degeneration, atrophy of the rotator cuff muscle, and retraction of the torn tendon. ${ }^{3)}$ Even after a successful repair, the poor quality of the ten- 
Lee et al. Partial Repair of Rotator Cuff Tears

Clinics in Orthopedic Surgery • Vol. 12, No. 3, $2020 \bullet$ www.ecios.org

don limits its ability to tolerate increased tension. Hence, retears are quite common for large to massive tears. ${ }^{4)}$

Partial repair has become a popular technique for irreparable rotator cuff tears since Burkhart et al. ${ }^{5)}$ introduced arthroscopic margin convergence based on the force couple theory in 1994. Several biomechanical and clinical studies have shown its effectiveness in reducing tension and strain of the torn tendon and have noted satisfactory outcomes of arthroscopic rotator cuff repair using the margin convergence technique. ${ }^{6,7)}$ However, a high retear rate $(45.5 \%)$ after arthroscopic partial repair has also been reported in large to massive rotator cuff tears. ${ }^{8}$ Thus, to overcome the high retear rate, medialization of the footprint of the rotator cuff designed to prevent overtension was introduced. ${ }^{9,10)}$ Medialization is a procedure shifting the anatomic footprint of the rotator cuff to the medial side of the humeral head by creating a new site of tendon attachment. ${ }^{4)}$

No clinical study has been conducted on the effectiveness of arthroscopic partial repair with medialization of the attachment site of the rotator cuff tendon. This study aimed to analyze the clinical and radiological outcomes of arthroscopic partial repair with medialization for large to massive posterosuperior rotator cuff tears and to evaluate the prognostic factors that affect rotator cuff healing. Our hypothesis was that arthroscopic partial repair with medialization can be a possible treatment option for irreparable large to massive posterosuperior rotator cuff tears.

\section{METHODS}

\section{Patient Selection}

This study is retrospective in nature and the protocol of this study was reviewed and approved by the Institutional Review Board of Eulji University Hospital (IRB No. EMC 2019-06-012). Written informed consents were obtained.

This study was performed between July 2012 and March 2016 on patients who underwent arthroscopic partial repair and were followed up for at least 2 years. According to the classification of DeOrio and Cofield, ${ }^{11)}$ tears $>3$ $\mathrm{cm}$ but $<5 \mathrm{~cm}$ were considered large, and a massive tear was defined as a full-thickness tear of 2 or more rotator cuff tendons or tears with a maximum diameter of $>5 \mathrm{~cm} .{ }^{3)} \mathrm{An}$ irreparable rotator cuff tear was defined as any rotator cuff tear that cannot be repaired with the original footprint above the greater tuberosity of the humerus. ${ }^{12)}$

The inclusion criteria were (1) a full-thickness supraspinatus and/or infraspinatus tear confirmed by preoperative magnetic resonance imaging (MRI) or magnetic resonance arthrography, (2) an arthroscopic partial rotator cuff repair with medialization of the attachment site of the rotator cuff, (3) use of the single-row modified MasonAllen technique, and (4) a $>3 \mathrm{~cm}$ tear in either the coronal or sagittal plane, which was measured and confirmed intraoperatively. The exclusion criteria were (1) complete repair of the rotator cuff, (2) patient's refusal to undergo postoperative MRI, (3) a subscapularis tear requiring repair, and (4) moderate to severe rotator cuff arthropathy (Hamada classification III, IV, or V). ${ }^{13)}$

Between July 2012 and March 2016, a total of 275 arthroscopic rotator cuff repairs were performed by a single senior surgeon (KWL) at our hospital. Among the 275 patients, 16 patients with a partial-thickness rotator cuff tear, 151 patients with a small to medium-sized rotator cuff tear, 8 patients who underwent complete repair, 24 patients who underwent a different surgical technique (i.e., suture-bridge technique), 13 patients who had a repaired subscapularis tear, and 5 patients who had moderate to severe rotator cuff arthropathy were excluded from this study. Of the remaining 58 patients, 9 patients who did not undergo postoperative MRI 12 months postoperatively to evaluate the cuff retear were also excluded, and 7 patients were lost during follow-up. Finally, 42 patients were enrolled in this study (Fig. 1).

\section{Surgical Technique}

All operations were carried out with general anesthesia. Patients were placed in the beach chair position. Preoperative intravenous antibiotics were administered. Diagnostic arthroscopy was performed using the routine portal. Biceps tenotomy was performed for symptomatic biceps tears involving $>50 \%$ of the tendon and for symptomatic, degenerative superior labral anterior and posterior lesions according to the age and activity level of the patient. In addition, acromioplasty was conducted when osteophytes were found under the acromion or the acromion had a hooked shape. For complete visualization, debridement was performed to remove the unhealthy tendon and to gain better access to the tendon tissues. The shape of tear was confirmed and the presence of delamination was identified during arthroscopic examination. The degree of tendon mobility in medial to lateral and posterior to anterior directions was well evaluated using a grasping tool. If the mobility of a tendon was insufficient for repair, procedures to mobilize the tendon were performed. A shaver and radiofrequency ablation device were used to conduct sufficient excursion of the torn tendon. The intra-articular release of the tendon-capsular interface, including superior capsulotomy, was conducted, as well as the tendon-bursal interface releases in the subacromial space. However, the 


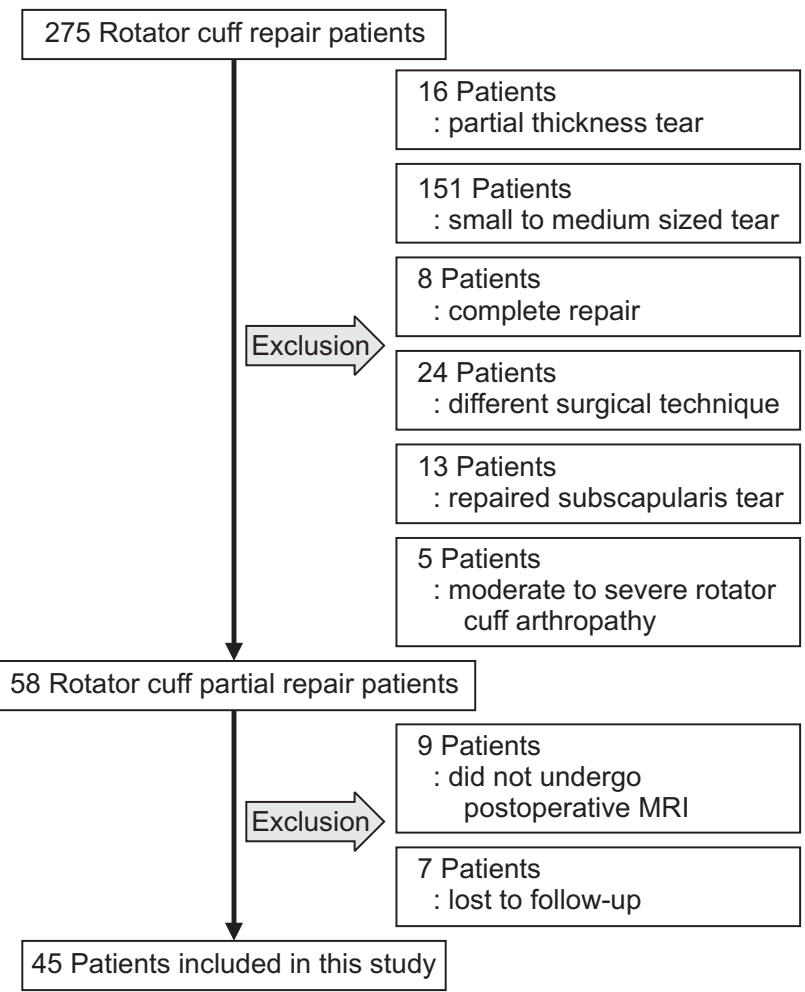

Fig. 1. Study flowchart. MRl: magnetic resonance imaging.

anterior or posterior interval slide procedure was not performed.

Medialization was performed based on whether the tendon cannot be pulled to the greater tuberosity footprint using a grasper or the degree of tension is excessive when pulled. Medialization was conducted if the medial to lateral length of the contact area of the tendon and bone was at least $10 \mathrm{~mm}$ when the retracted tendon was pulled as much as possible in a tension-free manner using a grasper. The humeral head articular cartilage in this contact area was scraped using a ring curette. Then, the medialization length was measured as the distance between the lateral border of the residual humeral articular cartilage and the medial border of the greater tuberosity footprint using a 3.4-mm ring curette.

After bone and tendon preparation, including medialization, arthroscopic partial cuff repair was performed using the single-row modified Mason-Allen repair. One or two 4.5- or 5.5-mm Healix BR anchors (DePuyMitek, Raynham, MA, USA) loaded with two No. 2 nonabsorbable braided sutures were inserted and placed between the just lateral side of the residual humeral articular cartilage and just the lateral side of the retracted tendon edge, vertically to the tendon edge toward the center of the lateral side of the acromion at $45^{\circ}$. If insertion of the anchor through the routine portal was difficult, it was inserted using the Neviaser portal.

One limb of the nonabsorbable suture was passed intra-articularly to the tendon in the subacromial space by the shuttle relay. The passed limb of the suture was retrieved in the bursal-to-articular direction by the same method. In this step, a horizontal loop was made on the cuff. The passed limb of the suture was retrieved just medial to the horizontal strand situated from the articular side to the bursal side of the cuff. Then, the unpassed limb of the suture was tied just medial to the horizontal loop above the tendon. Depending on the tear size, 1 or 2 additional sutures (7-8 $\mathrm{mm}$ in length) were performed.

\section{Rehabilitation}

All patients underwent identical rehabilitation, with outpatient follow-ups at 2 weeks, 6 weeks, 3 months, 6 months, 12 months, and 24 months. For the first 6 weeks, the patients wore abduction braces that maintained the shoulder at $30^{\circ}$ of abduction. The elbow joint, wrist joint, and finger exercises were carried out 1 day after surgery to prevent joint stiffness. The brace was removed 6 weeks postoperatively, with passive forward flexion of the arm that did not undergo surgery. Active joint exercises and active resistance muscle strengthening exercises using Thera Band (HCM-Hygenic, Batu Gajah, Malaysia) were started 3 months postoperatively. At 6 months postoperatively, the patients were allowed to participate in normal daily activities.

\section{Evaluation}

\section{Clinical evaluation}

All patients were evaluated both preoperatively and at least 2 years postoperatively using the visual analog scale (VAS), the University of California, Los Angeles (UCLA) shoulder rating scale, ${ }^{14)}$ Constant score,${ }^{15)}$ and active ROM. The VAS for pain during motion was rated from 0 to 10 , with 0 point indicating no pain and 10 points, pain. The UCLA is a 35-point scale, with 10 points for pain, 10 points for function, and 5 points each for motion, strength, and patient satisfaction. A score from 34 to 35 is considered an excellent result and a score from 29 to 33, a good result. Any score $<28$ is considered a poor result. The Constant score is a 100-point scoring system in which 35 points are allocated for subjective assessments of pain and function. The remaining 65 points are for objective assessments of range of movement and strength. For shoulder ROM, forward flexion, abduction, and external rotation were tested actively. External rotation of the shoulder was evaluated with the shoulder in adduction, the elbow in $90^{\circ}$ flexion, 
and the forearm in the neutral position. Both preoperative and postoperative clinical data and active $\mathrm{ROM}$ were measured using a goniometer in a blinded fashion by 2 physician assistants (BKS and JIW) who were not involved in this study; passive ROM was not measured.

\section{Radiological evaluation}

All 42 patients underwent a standardized MRI examination preoperatively. Postoperative MRI was performed on postoperative day 1 and additionally at least 12 months after operation (mean, 20.6 month; range, 12-38 months) to evaluate the integrity of the repaired tendon and intramuscular fatty degeneration. The MRI scans were reviewed in a blinded fashion by 1 experienced musculoskeletal radiologist (TJC) and 1 orthopedic surgeon (JHB) who were not involved in this study.

The repaired tendon was classified as follows: (1) healing success group: the tendon showing homogeneous low-intensity or partial high-intensity areas with sufficient thickness was regarded as intact; and (2) healing failure group: based on the comparison of the postoperative and last follow-up MRI, newly appeared discontinuity in more than 1 slice with a full-thickness tear was regarded as a retear. $^{16)}$

Fatty degeneration of the rotator cuff was evaluated by MRI using the global fatty degeneration index (GFDI). ${ }^{17)}$ Once the 3 muscle types were classified accordingly to the Goutallier classification, the mean of the 3 values was calculated to get GFDI.

In addition, the acromiohumeral distance (AHD) was measured in true anteroposterior view of the shoulder preoperatively and at the final follow-up to evaluate superior migration of the humeral head. The AHD was defined as the shortest distance between the dense cortical bone at the inferior aspect of the acromion and the subchondral cortex at the superior aspect of the humeral head (Fig. 2). ${ }^{18}$ One experienced musculoskeletal radiologist (TJC) and 1 orthopedic surgeon (JHB) each measured the AHD, and the mean of these 2 values was used for the analysis.

\section{Evaluation of preoperative prognostic factors affecting cuff healing}

To evaluate the prognostic factors for cuff healing, $42 \mathrm{pa}-$ tients were classified into the healing success and failure groups. The univariate and the multivariate analyses were performed for the following factors: age, sex, hand dominance, diabetes mellitus, hypertension, steroid injection, smoking, trauma history, intraoperative biceps procedure, symptom duration, preoperative clinical outcomes, preoperative fatty infiltration of cuff muscle, preoperative AHD, tear size, number of suture anchors used, and medialization length.

\section{Statistical Analysis}

Measurements are expressed as mean \pm standard deviation with a range for continuous variables that meet the normality assumption. The paired $t$-test or Wilcoxon signed rank test was used to compare clinical and radiological outcomes between preoperative and final follow-up examinations. In the univariate analysis, the Student $t$-test or Mann-Whitney $U$-test was used for analysis of continuous variables, and the chi-square test or Fisher exact test was used for categorical variables. In the multivariate analysis, logistic regression with a forward stepwise technique was performed for statistically significant factors in the univariate analysis. In addition, to determine the cutoff value of the preoperative AHD for successful rotator cuff healing, receiver operating characteristic (ROC) analysis with a calculation of the area under the ROC curve was performed. IBM SPSS ver. 20.0 (IBM Corp., Armonk, NY, USA) was used for all statistical analyses with $\alpha$ level set at 0.05 .

\section{RESULTS}

\section{Demographic Data}

The included patients were 22 men and 20 women (total, 42 patients) who underwent arthroscopic partial repair

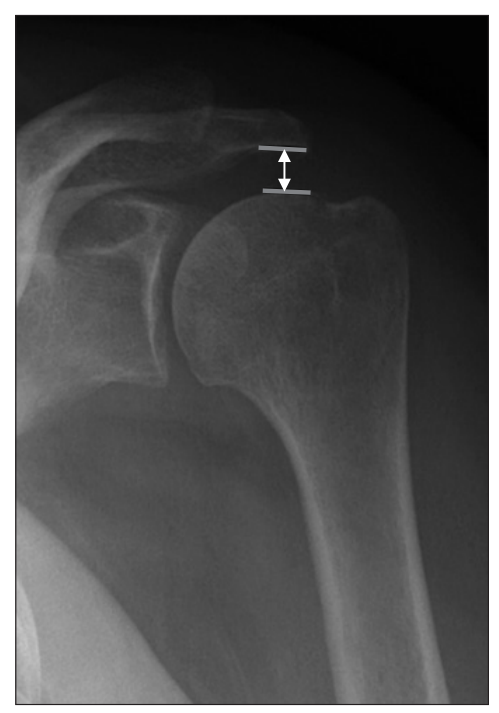

Fig. 2. The acromiohumeral distance was defined as the shortest distance between the dense cortical bone in the inferior aspect of the acromion and the subchondral cortex in the superior aspect of the humeral head (arrow). 
with medialization of the attachment site of the rotator cuff tendon. The mean patient age at the time of the operation was $61.2 \pm 9.1$ years (range, $31-78$ years), and the mean follow-up period was $35.4 \pm 7.3$ months (range, 25-55 months). The dominant side was affected in 34 patients. The average time between the start of symptoms and the surgical consultation was $10.4 \pm 4.3$ months (range, 5-62 months). Detailed medical history including the hand dominance, diabetes mellitus, hypertension, steroid injection, and smoking were reviewed (Table 1).

\section{Arthroscopic Findings}

The mean rotator cuff tear size, when measured at the longest distance, was $44.8 \pm 9.1 \mathrm{~mm}$ (range, 30-62 mm), and the mean medialization length was $8.8 \pm 1.5 \mathrm{~mm}$ (range, $6.2-13.6 \mathrm{~mm}$ ). The mean number of anchors used was 2.3 \pm 0.6 (range, $1-3)$ (Table 1$)$.

\section{Clinical Outcomes}

All 3 clinical scores showed significant improvement over the preoperative scores at the final follow-up. The mean VAS pain score was statistically significantly improved from $5.7 \pm 1.5$ preoperatively to $1.9 \pm 1.2$ postoperatively at the final follow-up. The mean UCLA score increased from 20.5 \pm 4.2 to $30.9 \pm 2.3$, and the mean Constant score increased

Table 1. Patient Demographics $(n=42)$

\begin{tabular}{lc}
\multicolumn{1}{c}{ Demographic } & Value \\
\hline Age (yr) & $61.2 \pm 9.1(31-78)$ \\
\hline Sex (male : female) & $22: 20$ \\
\hline Hand dominance (right : left) & $34: 8$ \\
\hline Diabetes mellitus (yes : no) & $35: 7$ \\
\hline Hypertension (yes : no) & $16: 26$ \\
\hline Steroid injection (yes : no) & $4: 38$ \\
\hline Smoking (yes : no) & $13: 29$ \\
\hline Trauma (yes : no) & $31: 11$ \\
\hline Biceps procedure (none : tenotomy) & $32: 10$ \\
\hline Follow-up period (mo) & $35.4 \pm 7.3(25-55)$ \\
\hline Symptom duration (mo) & $10.4 \pm 4.3(5-62)$ \\
\hline Tear size (mm) & $44.8 \pm 9.1(30-62)$ \\
\hline No. of suture anchors & $2.3 \pm 0.6(1-3)$ \\
\hline Medialization length (mm) & $8.8 \pm 1.5(6.2-13.6)$ \\
\hline
\end{tabular}

Values are presented as mean \pm standard deviation (range) unless otherwise indicated. from $41.2 \pm 6.7$ to $88.8 \pm 7.9$ ( $p<0.001$ for all). Further, active ROM (forward flexion, abduction, and external rotation) at the final follow-up were significantly improved compared to those before surgery (all $p<0.001$ ) (Table 2). All clinical outcomes were significantly improved compared to the preoperative state (all $p<0.001)$ (Table 2).

\section{Radiological Outcomes}

Rotator cuff fatty infiltration was measured using Goutallier's GFDI. The GFDI of the supraspinatus muscle, infraspinatus muscle, and subscapularis muscle before surgery was $2.0 \pm 0.4$; which was largely consistent with the postoperative value $(1.9 \pm 0.4)$ with no significant change $(p=$ 0.355 ) (Table 3). The mean AHD was $6.5 \pm 1.7 \mathrm{~mm}$ (range, $3.2-9.7 \mathrm{~mm}$ ) preoperatively and $6.3 \pm 1.6 \mathrm{~mm}$ (range, $2.8-9.5 \mathrm{~mm}$ ) at the final follow-up, showing no significant difference $(p=0.127)$ (Table 3$)$.

Based on the imaging study conducted at a minimum of 12 months after surgery, the healing success group (Fig. 3) comprised 32 patients (76.2\%), and the healing failure group (Fig. 4) comprised 10 patients (23.8\%). Both groups showed significant improvement of clinical outcomes at the final follow-up compared to the values before surgery (all $p<0.001$ ) (Table 4 ). Further, no significant differences were observed in postoperative clinical out-

Table 2. Comparison of the Preoperative and Final Follow-up Clinical Outcomes

\begin{tabular}{lccc}
\multicolumn{1}{c}{ Variable } & Preoperative & Final follow-up & $p$-value \\
VAS pain score & $5.7 \pm 1.5$ & $1.9 \pm 1.2$ & $<0.001$ \\
UCLA score & $20.5 \pm 4.2$ & $30.9 \pm 2.3$ & $<0.001$ \\
Constant score & $41.2 \pm 6.7$ & $88.8 \pm 7.9$ & $<0.001$ \\
\hline Forward flexion $\left(^{\circ}\right)$ & $131.5 \pm 49.6$ & $166.8 \pm 22.5$ & $<0.001$ \\
Abduction $\left(^{\circ}\right)$ & $126.6 \pm 47.7$ & $161.9 \pm 23.6$ & $<0.001$ \\
\hline External rotation $\left(^{\circ}\right)$ & $46 \pm 14$ & $53 \pm 15$ & $<0.001$ \\
\hline
\end{tabular}

Values are presented as mean \pm standard deviation.

VAS: visual analog scale, UCLA: University of California, Los Angeles.

Table 3. Pre- and Postoperative Fatty Infiltration of the Rotator Cuff and Acromiohumeral Distance

\begin{tabular}{cccc} 
Variable & Preoperative & Postoperative & $p$-value \\
$\begin{array}{cccc}\text { Global fatty } \\
\text { degeneration index }\end{array}$ & $2.0 \pm 0.4(1.0-2.9)$ & $1.9 \pm 0.4(1.1-2.7)$ & 0.355 \\
$\begin{array}{cccc}\text { Acromiohumeral } \\
\text { distance }(\mathrm{mm})\end{array}$ & $6.5 \pm 1.7(3.2-9.7)$ & $6.3 \pm 1.6(2.8-9.5)$ & 0.127 \\
\hline
\end{tabular}

Values are presented as mean \pm standard deviation (range). 
comes between the 2 groups (all $p>0.05$ ) (Table 4). No patients had nerve or vessel damage, wound site infection, and suture anchor problem.

\section{Factors Affecting Cuff Healing}

In the univariate analysis (Table 5), rotator cuff healing was affected by preoperative AHD $(p=0.043)$. Also, pre- operative AHD was revealed to be an independent prognostic factor affecting healing failure in the multivariate logistic regression analysis $(p=0.048)$. The cutoff value of preoperative AHD corresponding with the highest accuracy based on the ROC curve to predict successful rotator cuff healing was $5.3 \mathrm{~mm}$ (Fig. 5). The failure rate was significantly higher in patients with preoperative AHD $<5.3$
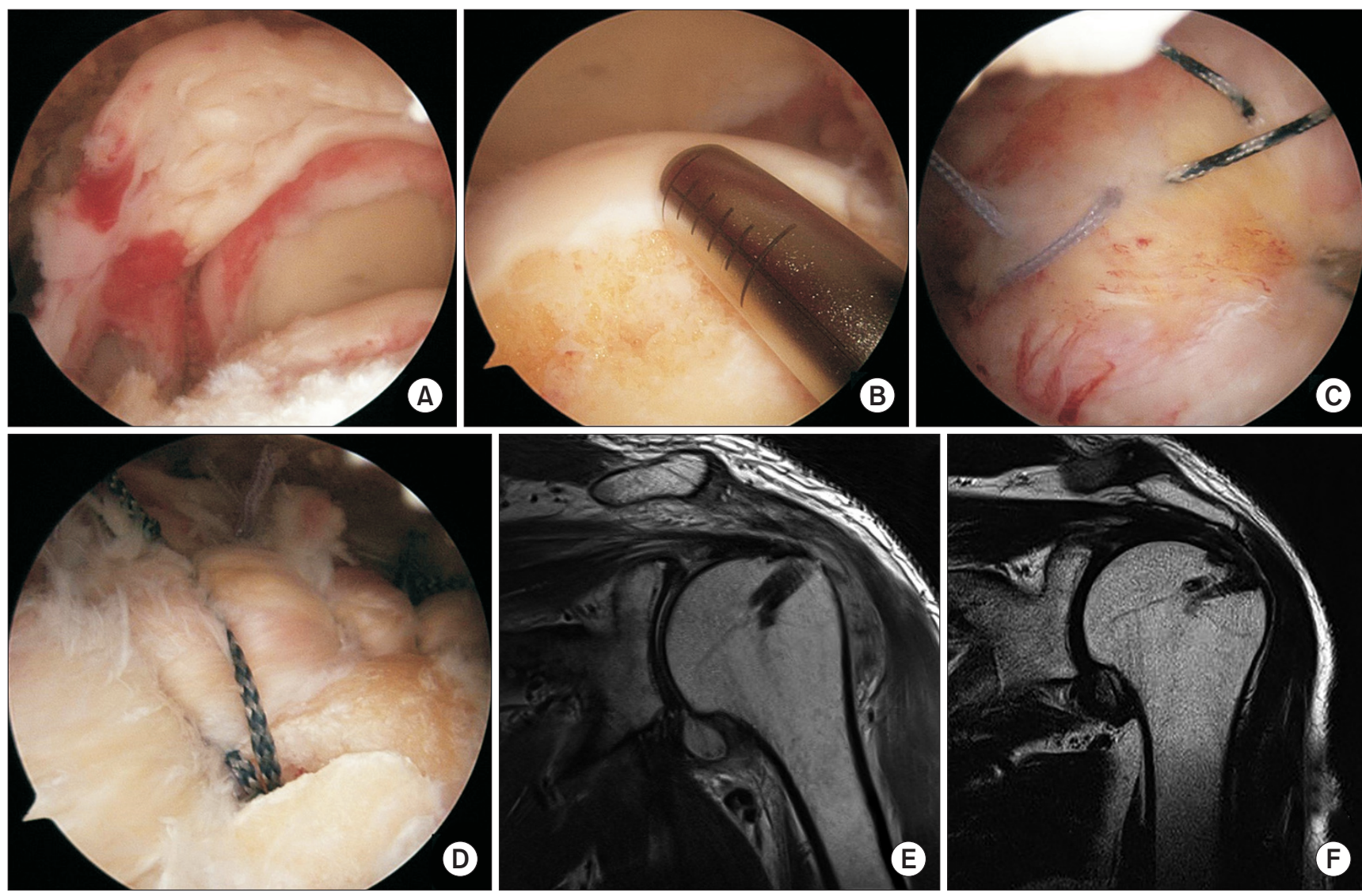

Fig. 3. Arthroscopic views showing an irreparable massive rotator cuff tear (A) after medialization (B) and repair with the single-row modified MasonAllen method (C, D). (E) Postoperative magnetic resonance imaging showing the well-repaired state. (F) Magnetic resonance imaging at 16 months after surgery showing the well-healed state.


Fig. 4. Arthroscopic views showing an irreparable massive rotator cuff tear (A) after repair with the single-row modified Mason-Allen method (B). (C) Postoperative magnetic resonance imaging showing the well-repaired state. (D) Magnetic resonance imaging at 13 months after surgery showing the reruptured state. 
Lee et al. Partial Repair of Rotator Cuff Tears

Clinics in Orthopedic Surgery • Vol. 12, No. 3, $2020 \bullet$ www.ecios.org

Table 4. Comparison of the Preoperative and Final Follow-up Clinical Outcomes between the Healing Success and Failure Groups

\begin{tabular}{|c|c|c|c|}
\hline Variable & Preoperative & Final follow-up & $p$-value \\
\hline Visual analog scale & & & 0.260 \\
\hline Healing success group & $5.2 \pm 1.5$ & $1.8 \pm 0.9$ & $<0.001$ \\
\hline Healing failure group & $4.5 \pm 1.0$ & $1.4 \pm 0.8$ & $<0.001$ \\
\hline UCLA score & & & 0.561 \\
\hline Healing success group & $22.6 \pm 3.2$ & $32.1 \pm 2.6$ & $<0.001$ \\
\hline Healing failure group & $22.7 \pm 3.8$ & $31.5 \pm 3.9$ & $<0.001$ \\
\hline Constant score & & & 0.278 \\
\hline Healing success group & $44.3 \pm 12.1$ & $89.4 \pm 6.3$ & $<0.001$ \\
\hline Healing failure group & $45.5 \pm 9.0$ & $86.7 \pm 8.1$ & $<0.001$ \\
\hline Forward flexion $\left({ }^{\circ}\right)$ & & & 0.320 \\
\hline Healing success group & $132.5 \pm 48.6$ & $168.6 \pm 20.5$ & $<0.001$ \\
\hline Healing failure group & $128.0 \pm 53.5$ & $160.5 \pm 27.1$ & $<0.001$ \\
\hline Abduction $\left({ }^{\circ}\right)$ & & & 0.476 \\
\hline Healing success group & $128.9 \pm 47.6$ & $162.3 \pm 16.3$ & $<0.001$ \\
\hline Healing failure group & $121.1 \pm 49.5$ & $159.8 \pm 14.6$ & $<0.001$ \\
\hline External rotation, deg & & & 0.884 \\
\hline Healing success group & $44.3 \pm 15.2$ & $50.3 \pm 13.9$ & $<0.001$ \\
\hline Healing failure group & $41.1 \pm 10.2$ & $53.6 \pm 12.1$ & $<0.001$ \\
\hline
\end{tabular}

Values are presented as mean \pm standard deviation.

UCLA: University of California, Los Angeles.

$\mathrm{mm}(4 / 10,40.0 \%)$ than in those with preoperative AHD $\geq 5.3 \mathrm{~mm}(6 / 32,18.8 \% ; p=0.040)$.

\section{DISCUSSION}

In this study, we evaluated the clinical and radiological outcomes of arthroscopic partial repair with medialization of the attachment site of the rotator cuff tendon in patients with irreparable large to massive posterosuperior rotator cuff tears. Arthroscopic partial repair with medialization for irreparable large to massive posterosuperior rotator cuff tears was associated with good clinical outcomes and good structural integrity. Functional outcomes showed improvements in the mean VAS, UCLA, and Constant score after the procedure, while the failure rate was $23.8 \%$ based on the radiological outcomes.

In large to massive rotator cuff tears, it is difficult to reattach the torn rotator cuff tendon to the anatomical footprint. Even if the torn tendon can be retracted to the original footprint, undue tension commonly occurs. To reduce such tension, medialization of the insertion site of the rotator cuff tendon was suggested. ${ }^{4)}$ By shifting the anatomic insertion of the rotator cuff to the medial side of the cartilage of the humeral head, the medialization procedure allows surgical repair of the retracted tendons. However, medialization affects the shoulder ROM by reducing the moment arm at the cuff tendon and decreasing the articular surface area of the humeral head. Liu et al. ${ }^{19}$ reported that medialization of the supraspinatus tendon of $17 \mathrm{~mm}$ or more resulted in moment arm reduction in a biomechanical study. They recommended reattachment of the tendon within $10 \mathrm{~mm}$ of its footprint. In our study, with medialization, the lateral to medial length for the tendon to bone attachment site was a mean of $8.8 \pm 1.5 \mathrm{~mm}$ (range, 6.2-13.6 mm). Both healing success and failure groups showed significant increases in forward flexion, abduction, and external rotation.

All surgical procedures were performed using the 
Lee et al. Partial Repair of Rotator Cuff Tears

Clinics in Orthopedic Surgery • Vol. 12, No. 3, $2020 \bullet$ www.ecios.org

Table 5. Comparison of the Healing Success and Healing Failure Groups in Univariate Analysis

\begin{tabular}{|c|c|c|c|}
\hline Variable & Healing success $(n=32)$ & Healing failure $(n=10)$ & $p$-value \\
\hline Age (yr) & $60.1 \pm 10.1$ & $64.7 \pm 5.2$ & 0.067 \\
\hline Sex (male : female) & $16: 16$ & $6: 4$ & 0.723 \\
\hline Hand dominance (right : left) & $26: 6$ & $8: 2$ & 0.960 \\
\hline Diabetes mellitus (yes : no) & $27: 5$ & $8: 2$ & 0.959 \\
\hline Hypertension (yes : no) & $19: 13$ & $7: 3$ & 0.715 \\
\hline Steroid injection (yes : no) & $28: 4$ & $10: 0$ & 0.321 \\
\hline Smoking (yes : no) & $23: 9$ & $6: 4$ & 0.697 \\
\hline Trauma (yes : no) & $9: 23$ & $2: 8$ & 0.972 \\
\hline Biceps procedure (none : tenotomy) & $25: 7$ & $7: 3$ & 0.476 \\
\hline Symptom duration (mo) & $10.8 \pm 21.2$ & $12.4 \pm 19.9$ & 0.732 \\
\hline \multicolumn{4}{|l|}{ Preoperative } \\
\hline Visual analog scale & $5.2 \pm 1.5$ & $4.5 \pm 1.0$ & 0.204 \\
\hline UCLA score & $22.6 \pm 3.2$ & $22.7 \pm 3.8$ & 0.950 \\
\hline Constant score & $44.3 \pm 12.1$ & $45.5 \pm 9.0$ & 0.766 \\
\hline Forward flexion $\left({ }^{\circ}\right)$ & $132.5 \pm 48.6$ & $128.0 \pm 53.5$ & 0.804 \\
\hline Abduction $\left({ }^{\circ}\right)$ & $128.9 \pm 47.6$ & $121.1 \pm 49.5$ & 0.652 \\
\hline \multicolumn{4}{|l|}{ Fatty infiltration } \\
\hline Supraspinatus & $2.5 \pm 0.9$ & $2.9 \pm 0.7$ & 0.169 \\
\hline Infraspinatus & $1.0 \pm 0.7$ & $1.2 \pm 0.8$ & 0.410 \\
\hline Subscapularis & $0.9 \pm 0.8$ & $1.1 \pm 0.5$ & 0.436 \\
\hline Preoperative AHD & $6.8 \pm 1.6$ & $5.6 \pm 1.8$ & $0.043^{*}$ \\
\hline Tear size $(\mathrm{mm})$ & $44.9 \pm 9.4$ & $44.1 \pm 9.3$ & 0.799 \\
\hline No. of suture anchors & $2.1 \pm 0.8$ & $2.4 \pm 0.9$ & 0.387 \\
\hline Medialization length (mm) & $8.6 \pm 1.7$ & $8.9 \pm 0.9$ & 0.417 \\
\hline
\end{tabular}

Values are presented as mean \pm standard deviation.

UCLA: University of California, Los Angeles, AHD: acromiohumeral distance.

*Statistically significant difference between groups $(p<0.05)$.

single-row modified Mason-Allen technique, which has been reported to be biomechanically superior to other suture techniques. ${ }^{20)}$ The interval slide technique was not performed in our study. In some studies, ${ }^{21-23)}$ the interval slide technique has been reported to show good clinical results. However, Kim et al. ${ }^{24)}$ indicated that concomitant anterior and posterior interval slide procedures could increase the risk of devascularization of the torn tendon. In addition, this technique showed a high retear rate after an aggressive release.

A variety of prognostic factors have been reported to be associated with cuff healing after rotator cuff repair, including preoperative superior migration of the humeral head, subscapularis tear, glenohumeral arthritis, decreased shoulder ROM, age, sex, symptom duration, tear size, and fatty infiltration of the cuff muscle. ${ }^{25,26)}$ In the current study, only preoperative AHD was found to be an independent prognostic factor that has negative influence on the structural integrity in the univariate and the multivariate analyses. Decreased AHD may induce chronic injuries and affect vascularity and structural integrity of the tendon, ${ }^{27)}$ and decreased vascularity reduces the heal- 


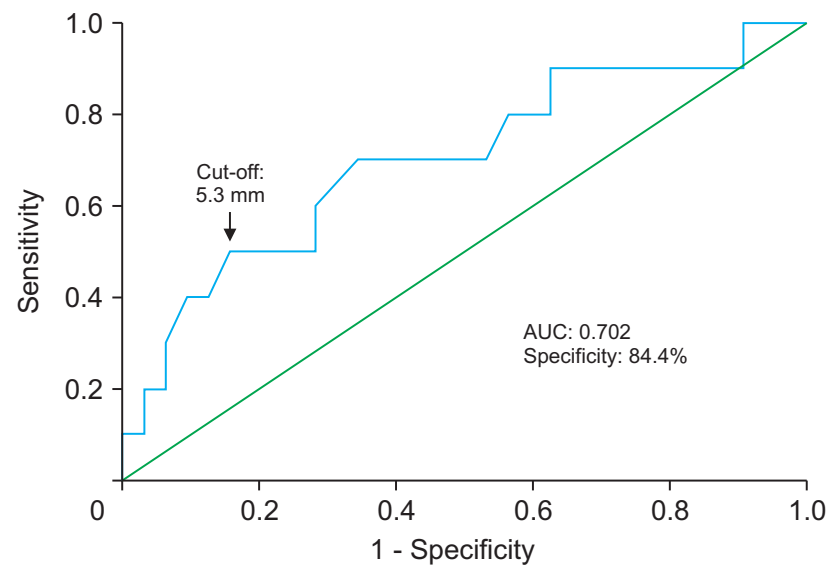

Fig. 5. Receiver operating characteristic curve for the prediction of rotator cuff healing by the preoperative acromiohumeral distance. The cutoff value to predict failure of rotator cuff healing after arthroscopic partial repair was $5.3 \mathrm{~mm}$. AUC: area under the curve.

ing potential of the tendon after cuff repair. Consequently, decreased AHD increases the risk of postoperative retear. ${ }^{2)}$ In a study that analyzed the prognostic factors for a repair of massive rotator cuff tears using the suture-bridge technique, the AHD measured with anteroposterior radiographs significantly differed between the intact group and retear group. ${ }^{28)}$ However, this study only performed univariate analysis without any multivariate analysis. Another study that performed a multivariable analysis reported that preoperative AHD is an independent predictive factor for retear, where the risk of postoperative retear increases when preoperative AHD is $<7 \mathrm{~mm} .^{2)}$ However, the study was limited in that it did not reflect patients' clinical outcomes. Further, there has been a report that it is impossible to repair rotator cuffs with preoperative AHD $<6-7$ $\mathrm{mm} .{ }^{3)}$ In our study, the cutoff value for preoperative AHD related to healing failure was determined to be $5.3 \mathrm{~mm}$. Patients with a preoperative AHD of $<5.3 \mathrm{~mm}$ showed a higher failure rate than those with a preoperative AHD of $\geq 5.3 \mathrm{~mm}$. It appears that arthroscopic partial repair with medialization improves healing potential by reducing tension even in the rotator cuff tear with a preoperative AHD of $<7 \mathrm{~mm}$. However, subtle differences in the angle of Xray and shoulder anatomy in each patient could affect the measurement of AHD.

Despite extensive research, healing failure after arthroscopic partial repair has yet to be overcome. However, several studies have reported that clinical outcomes are improved even with healing failure after partial repair. ${ }^{8,29,30)}$ In our study, all clinical outcomes were found to be improved compared to the preoperative state in the healing failure group. One reason for this phenomenon is specu- lated to be that postoperative recovery of force couple leads to a balanced distribution of force, thereby improving strength. This suggests that arthroscopic partial repair can be a superior surgical option to other techniques for irreparable large to massive rotator cuff tears despite the high retear rate.

This study also has several limitations. First, it is a retrospective study, not a prospective randomized controlled study. Second, a comparative study was not possible due to the lack of a control group using other surgical techniques. Third, a relatively small number of patients were selected, and the mean follow-up period was relatively short. Therefore, future studies with a larger number of patients and longer follow-up period are necessary. Nonetheless, the most important strength of the present study is that it confirmed that arthroscopic partial repair with medialization could be a good treatment option for irreparable large to massive posterosuperior rotator cuff tears. Further, all procedures in this study were performed by the same surgeon using the same technique.

In conclusion, arthroscopic partial repair with medialization for irreparable large to massive posterosuperior rotator cuff tears led to improved clinical outcomes compared to the preoperative state. The healing failure rate was $23.8 \%$, but even the patients in the healing failure group showed clinical improvement compared to their preoperative state. The univariate and multivariate analyses identified preoperative AHD as the independent prognostic factor affecting rotator cuff healing. The preoperative AHD of $5.3 \mathrm{~mm}$ was identified as the reference value associated with healing failure. Therefore, it would be desirable to perform surgery for irreparable large to massive posterosuperior rotator cuff tears when AHD is $\geq 5.3$ $\mathrm{mm}$ to ensure successful healing; however, even if AHD is $<5.3 \mathrm{~mm}$, postoperative clinical outcomes could still be improved. Therefore, arthroscopic partial repair with medialization can be a considerable treatment option for patients with irreparable large to massive posterosuperior rotator cuff tears.

\section{CONFLICT OF INTEREST}

No potential conflict of interest relevant to this article was reported.

\section{ACKNOWLEDGEMENTS}

We appreciate Bong-Ki Song, PA (Department of Orthopedics, Eulji University Hospital), Ji-In Woo, PA (Department of Orthopedics, Eulji University Hospital), Tong-Jin 
Lee et al. Partial Repair of Rotator Cuff Tears

Clinics in Orthopedic Surgery • Vol. 12, No. 3, $2020 \bullet$ www.ecios.org

Cheon, MD (Department of Radiology, Eulji University Hospital) and Jin-Hyun Bae, MD (Department of Ortho- pedics, Eulji University Hospital) for their contribution to this study.

\section{REFERENCES}

1. McKee MD, Yoo DJ. The effect of surgery for rotator cuff disease on general health status: results of a prospective trial. J Bone Joint Surg Am. 2000;82(7):970-9.

2. Shin YK, Ryu KN, Park JS, Jin W, Park SY, Yoon YC. Predictive factors of retear in patients with repaired rotator cuff tear on shoulder MRI. AJR Am J Roentgenol. 2018;210(1):134-41.

3. Gerber C, Fuchs B, Hodler J. The results of repair of massive tears of the rotator cuff. J Bone Joint Surg Am. 2000;82(4):505-15.

4. Kim YK, Jung KH, Won JS, Cho SH. Medialized repair for retracted rotator cuff tears. J Shoulder Elbow Surg. 2017;26(8):1432-40.

5. Burkhart SS, Nottage WM, Ogilvie-Harris DJ, Kohn HS, Pachelli A. Partial repair of irreparable rotator cuff tears. Arthroscopy. 1994;10(4):363-70.

6. Mazzocca AD, Bollier M, Fehsenfeld D, et al. Biomechanical evaluation of margin convergence. Arthroscopy. 2011;27(3):330-8.

7. Kim SJ, Lee IS, Kim SH, Lee WY, Chun YM. Arthroscopic partial repair of irreparable large to massive rotator cuff tears. Arthroscopy. 2012;28(6):761-8.

8. Yoo JC, Ahn JH, Koh KH, Lim KS. Rotator cuff integrity after arthroscopic repair for large tears with less-than-optimal footprint coverage. Arthroscopy. 2009;25(10):1093-100.

9. Davidson PA, Rivenburgh DW. Rotator cuff repair tension as a determinant of functional outcome. J Shoulder Elbow Surg. 2000;9(6):502-6.

10. Thorsness R, Romeo A. Massive rotator cuff tears: trends in surgical management. Orthopedics. 2016;39(3):145-51.

11. Cofield RH. Rotator cuff disease of the shoulder. J Bone Joint Surg Am. 1985;67(6):974-9.

12. Gerber C, Wirth SH, Farshad M. Treatment options for massive rotator cuff tears. J Shoulder Elbow Surg. 2011;20(2 Suppl):S20-9.

13. Hamada K, Fukuda H, Mikasa M, Kobayashi Y. Roentgenographic findings in massive rotator cuff tears. A long-term observation. Clin Orthop Relat Res. 1990;(254):92-6.

14. Ellman H, Hanker G, Bayer M. Repair of the rotator cuff. End-result study of factors influencing reconstruction. J Bone Joint Surg Am. 1986;68(8):1136-44.
15. Bankes MJ, Crossman JE, Emery RJ. A standard method of shoulder strength measurement for the Constant score with a spring balance. J Shoulder Elbow Surg. 1998;7(2):116-21.

16. Heuberer PR, Kolblinger R, Buchleitner S, et al. Arthroscopic management of massive rotator cuff tears: an evaluation of debridement, complete, and partial repair with and without force couple restoration. Knee Surg Sports Traumatol Arthrosc. 2016;24(12):3828-37.

17. Goutallier D, Postel JM, Gleyze P, Leguilloux P, Van Driessche $S$. Influence of cuff muscle fatty degeneration on anatomic and functional outcomes after simple suture of fullthickness tears. J Shoulder Elbow Surg. 2003;12(6):550-4.

18. Saupe N, Pfirrmann CW, Schmid MR, Jost B, Werner CM, Zanetti M. Association between rotator cuff abnormalities and reduced acromiohumeral distance. AJR Am J Roentgenol. 2006;187(2):376-82.

19. Liu J, Hughes RE, O'Driscoll SW, An KN. Biomechanical effect of medial advancement of the supraspinatus tendon: a study in cadavera. J Bone Joint Surg Am. 1998;80(6):853-9.

20. Ma CB, MacGillivray JD, Clabeaux J, Lee S, Otis JC. Biomechanical evaluation of arthroscopic rotator cuff stitches. J Bone Joint Surg Am. 2004;86(6):1211-6.

21. Berdusco R, Trantalis JN, Nelson AA, et al. Arthroscopic repair of massive, contracted, immobile tears using interval slides: clinical and MRI structural follow-up. Knee Surg Sports Traumatol Arthrosc. 2015;23(2):502-7.

22. Lo IK, Burkhart SS. The interval slide in continuity: a method of mobilizing the anterosuperior rotator cuff without disrupting the tear margins. Arthroscopy. 2004;20(4):43541.

23. Lo IK, Burkhart SS. Arthroscopic repair of massive, contracted, immobile rotator cuff tears using single and double interval slides: technique and preliminary results. Arthroscopy. 2004;20(1):22-33.

24. Kim SJ, Kim SH, Lee SK, Seo JW, Chun YM. Arthroscopic repair of massive contracted rotator cuff tears: aggressive release with anterior and posterior interval slides do not improve cuff healing and integrity. J Bone Joint Surg Am. 2013;95(16):1482-8.

25. Klinger HM, Steckel H, Ernstberger T, Baums MH. Arthroscopic debridement of massive rotator cuff tears: negative prognostic factors. Arch Orthop Trauma Surg. 2005;125(4):261-6. 
Lee et al. Partial Repair of Rotator Cuff Tears

Clinics in Orthopedic Surgery • Vol. 12, No. 3, $2020 \bullet$ www.ecios.org

26. Nho SJ, Brown BS, Lyman S, Adler RS, Altchek DW, MacGillivray JD. Prospective analysis of arthroscopic rotator cuff repair: prognostic factors affecting clinical and ultrasound outcome. J Shoulder Elbow Surg. 2009;18(1):13-20.

27. Levy O, Relwani J, Zaman T, Even T, Venkateswaran B, Copeland S. Measurement of blood flow in the rotator cuff using laser Doppler flowmetry. J Bone Joint Surg Br. 2008;90(7):893-8.

28. Kim JR, Cho YS, Ryu KJ, Kim JH. Clinical and radiographic outcomes after arthroscopic repair of massive rotator cuff tears using a suture bridge technique: assessment of repair integrity on magnetic resonance imaging. Am J Sports Med. 2012;40(4):786-93.

29. Galatz LM, Ball CM, Teefey SA, Middleton WD, Yamaguchi $\mathrm{K}$. The outcome and repair integrity of completely arthroscopically repaired large and massive rotator cuff tears. J Bone Joint Surg Am. 2004;86(2):219-24.

30. Chung SW, Kim JY, Kim MH, Kim SH, Oh JH. Arthroscopic repair of massive rotator cuff tears: outcome and analysis of factors associated with healing failure or poor postoperative function. Am J Sports Med. 2013;41(7):1674-83. 